\title{
Summer Learning Loss among Elementary School Children with Reading Disabilities
}

\author{
Jessica Menard \\ University of Windsor \\ Alexander M. Wilson \\ Mount Allison University
}

\begin{abstract}
This study investigated whether students with reading disabilities (RD) showed greater regression in reading skills than did non-RD students over the summer vacation. The RD group consisted of 30 students in grades 4 to 6 from a private school for students with learning disabilities and a comparison group of 30 average readers in grades 4 to 6 attending a public school. All students were tested in May/June and September on measures of reading achievement, phonological processing, and oral receptive vocabulary. Significant regression in the RD group's scores was found on speed of sight word reading, speeded phonological decoding, and untimed sight word reading. These results suggested that students with $R D$ tend to decline in areas that require automatic reading skills. Implications for students with $R D$ in relation to periods of extended absence from formal literacy instruction are discussed.
\end{abstract}

Summer learning loss, or summer regression, refers to a drop in test scores and/or a loss of acquired skills following the July/August break from school that is part of the traditional school calendar. In their meta-analysis of summer learning loss, Cooper, Nye, Charlton, Lindsay, and Greathouse (1996) concluded that regression in achievement occurs across a broad age range, affects mathematics skills more than reading skills, worsens with increasing age, and has a greater impact on students from low-income families. According to Cooper (2003), the assumption that children learn best when instruction is continuous is at the heart of the summer regression phenomenon. Cooper believed that the 2-month break in the school year disrupts the rhythm of instruction, leads to forgetting learned skills, and requires a significant amount of remediation upon returning to school in the fall.

Summer learning loss has been most extensively studied as it relates to differences in socioeconomic status. For example, Alexander, Entwisle, and Olson (2007) found that the 
achievement gap between high- and low-SES students at Grade 9 was mainly attributable to differential summer learning and retention during elementary school, and the achievement gap in reading and mathematics was predictive of whether students go to and/or complete college and of high school completion rates. Other studies looking at SES and summer regression provide support for the point that higher SES can have a protective effect against summer learning loss (e.g., Alexander, Entwisle, \& Olson, 2001; Allington \& McGill-Franzen, 2003; Cooper et al., 1996; Entwisle \& Alexander, 1992; Kim, 2004; McGill-Franzen \& Allington, 2008). The finding that low-SES students experience greater academic regression over the summer is well established. A more focused link between reading achievement and summer vacation, especially in struggling readers, has yet to be firmly established.

Reading achievement depends on a student's level of proficiency in areas such as phonological processing, phonological awareness, reading fluency, vocabulary, and reading comprehension. Phonological processing refers to the use of phonological information in processing written and oral language (Wagner \& Torgesen, 1987). Wagner and Torgesen (1987) proposed that phonological processing plays a causal role in learning to read and in reading difficulties experienced by individuals with reading disabilities (RD). Troia (2004) suggested that RD appears because of students' diminished capacity for phonological processing by affecting the way in which cognitive resources are allocated. A key component of phonological processing is phonological, or phonemic, awareness. This refers to an individual's possession of the knowledge that the speech stream consists of a sequence of sounds-specifically phonemes, the smallest unit of sound (Yopp \& Yopp, 2000). Students with RD have a fundamental problem in acquiring awareness of the phonemic structure of language (Pratt \& Brady, 1988), and children who are better at detecting rhymes and phonemes are quicker in learning to read (Anthony \& Lonigan, 2004).

Reading fluency refers to the speed or rate of reading (Mather \& Goldstein, 2001). Sight word reading refers to the process by which words are recognized quickly, based on how they look, thus reducing the need for effortful decoding to only those words that are novel to the reader (Ehri, 2005). From Ehri's (2005) perspective, the ability to read words automatically by sight is a key to fluency and to skilled reading. As for reading comprehension, McBride-Chang, Manis, Seidenberg, Custodio, and Doi (1993) have argued that good reading comprehension happens only in the presence of facility, not just minimal ability, with word reading and that a speeded reading rate may optimize the intake of ideas presented in a text. They suggest that this automaticity with reading comes from print exposure, measured by testing students' familiarity with print material using a revised version of the Title Recognition Test (Cunningham \& Stanovich, 1990). Both disabled and non-disabled readers who scored higher on the revised Title Recognition Test also tended to have better word recognition skills. This lends support to the idea that increased exposure to print material has a facilitative effect on reading proficiency. Students with RD tend not to read for pleasure because, by the nature of their disability, they find this task arduous. Given that they lack the print exposure that is more likely to be gained by their non-RD peers (Grant, Wilson, \& Gottardo, 2007), students with RD are likely to lack the automaticity needed for optimal intake of print materials.

As children move through the middle grades (4 to 8 ), they begin a critical shift between learning to decode and become fluent with text to the application of these skills to reading comprehension. At this age, students should be making the transition from "learning to read" to "reading to learn" (Chall, 1983). Ideally, it is during this time that students begin to acquire a store of background knowledge and a growing vocabulary by reading a wide variety of materials. 
Whether one argues that reading develops in stages (e.g., Chall, 1983; Ehri, 2005) or in a more blended manner such as in the Simple View of Reading (Hoover \& Gough, 1990), it remains that reading comprehension depends on adequate decoding, sight word knowledge, and automaticity.

Given that students with RD experience significant difficulties in many of the skills needed for successful reading, those with RD appear to be particularly at risk for summer learning loss since their grasp of reading-related foundation skills is not as strong as their non-RD peers from the beginning (Fletcher, Lyon, Fuchs, \& Barnes, 2007). For example, it has been suggested that the summer break can have a greater negative impact on the learning of children with special education needs (Cooper, 2003), although the evidence is currently limited. In an early study, Cornelius and Semmel (1982) found that students with learning disabilities in general tended to lose about three months in terms of grade-equivalent reading scores during the summer. Of those children classified as having learning disabilities, about $80 \%$ have their primary problems in learning to read (Lyon, 1996). It appears that students with RD are less likely to engage in less structured reading activities over the summer months as most do not appear to read for pleasure (Grant et al., 2007; McBride-Chang et al., 1993), and the amount of reading practice outside the classroom appears to differentiate students with RD from average readers (Chard, Vaughn, \& Tyler, 2002).

Cornelius and Semmel (1982) found that participation in summer reading programs, especially those that occurred near the end of the summer, could lessen the effect of summer vacation on regression in students with learning disabilities. However, their study did not include a nontreatment comparison group and the researchers appeared to group learning disabilities together rather than limit their scope to those with RD. Working from an intervention perspective, Kim (2006) conducted an experimental study to examine the effects of a voluntary summer reading intervention on Grade 4 students' reading achievement. Kim found that the magnitude of the effect of providing books to students over the summer and encouraging them to read was even greater in non-fluent readers than in fluent readers, suggesting that non-fluent readers can benefit from reading-based summer programming. A follow-up to this study by Kim and White (2008) suggested that providing books for summer reading in addition to parent scaffolding of reading skills contributes to an even greater effect of summer intervention in students in general.

Finally, Graham, McNamara, and Van Lankveld (2011) investigated the efficacy of a summer family literacy program in improving the reading achievement of at-risk students. Students deemed to be at high risk in their study included those with lower academic achievement due to learning disabilities and/or language impairments, lower SES, or learning in a non-native language. The effect of participating in a literacy-based program was a reversal in the summer learning loss expectancy for at-risk children, meaning that the scores of these at-risk children actually improved across the summer. While this finding is encouraging, it should be noted that the children who participated in this program were in Kindergarten at the time (mean age was 55 months). This represents a very early intervention, and floor effects are therefore possible. Graham et al. (2011) also acknowledged that their sample size of 14 was quite small and that their study did not include a control group. However, the finding that the children who participated in this summer intervention did not demonstrate summer reading regression is important to note, as it suggests that at-risk children should be able to avoid summer regression if an intervention were in place for them.

While research has investigated summer regression in reading skills of students in general, and in less affluent and/or struggling readers, studies of the effects of summer vacation on students with specific RD appear to be lacking. Therefore, the purpose of the current study was to 
examine the differential retention rates of specific literacy skills over summer vacation in students with a diagnosis of RD as compared to their typically-achieving peers. We expected that the reading achievement scores of both the RD and non-RD students would decline over the summer months (in line with the meta-analytic findings of Cooper et al., 1996), but the scores of the RD group would regress to a significantly greater extent than those of the non-RD comparison group, signifying a greater degree of summer learning loss in students with RD who do not receive structured reading intervention over the summer vacation.

\section{Method}

\section{Participants}

RD group. The RD sample consisted of 30 students in grades 4 to 6 who were attending a private school for students with learning disabilities in Western Canada. These students were enrolled in classes of approximately 15 children, and teachers with expertise in learning disabilities tailored instruction to their specific learning needs. To be eligible for the RD group, a student had to have a full psycho-educational assessment that demonstrated a reading disability since the early years of schooling, as well as no history of attention deficit/hyperactivity disorder or other mental health problems. The RD group included 21 boys and 9 girls, with ages ranging from 9 years, 6 months to 12 years, 6 months ( $M=10$ years, 8 months) at the initial testing period. During the May/June testing period, 15 RD students were in Grade 4, 9 were in Grade 5, and 6 were in Grade 6. All RD group students successfully progressed to the subsequent grade in September.

Comparison group. The comparison group consisted of 30 students in grades 4 to 6 attending a public elementary school in Eastern Canada. These students were enrolled in regular education classes, with approximately 25 students per class. Classroom teachers nominated comparison group students as being average or at grade level with respect to overall reading skills and having no history of learning, attention, or mental health problems. The comparison group included 15 boys and 15 girls, with ages ranging from 9 years, 6 months to 12 years, 6 months ( $M=11$ years, 2 months) at the onset of the study. During the May/June testing period, 10 comparison group students were in Grade 4, 10 were in Grade 5, and 10 were in Grade 6. All comparison group students successfully progressed to the subsequent grade in September.

\section{Materials}

The students in both groups were tested using a battery of eight tests, encompassing reading achievement, phonological processing, and oral receptive vocabulary. The following measures were included in the test battery.

Comprehensive Test of Phonological Processing (CTOPP; Wagner, Torgesen, \& Rashotte, 1999). The Elision subtest is a 20 -item test of phonological processing that tests an examinee's ability to say a word and then say what remains after omitting designated sounds. The reported alpha values for this subtest range from 0.89 to 0.91 (p. 69) across the age groups tested in the current study, and reported test-retest reliability is 0.79 (p. 74). The Blending Words subtest is a 20 -item test of phonological processing that measures a participant's ability to listen to a series of tape-recorded sounds and put the separate sounds together to make a whole word. Reported alpha values for this subtest range from 0.83 to 0.87 (p. 69) across the age groups tested, and the reported test-retest reliability is 0.72 (p. 74). 
Woodcock Reading Mastery Test-Revised (WRMT-R; Woodcock, 1998). The Word Attack subtest is a test of phonological decoding that measures an examinee's ability to name isolated nonwords (pronounceable letter combinations that are not actually words). The reported split-half reliability for the Word Attack subtest is 0.89 (p. 99). The Word Identification subtest evaluates an examinee's ability to identify real words in isolation. The reported split-half reliability for this subtest is 0.91 (p. 99). The Passage Comprehension subtest requires that examinees read silently a series of paragraphs and supply a missing key word for each. The reported split-half reliability for the Passage Comprehension test is 0.92 (p. 99). For all three of the WRMT-R subtests, Form G was administered in May/June and Form $\mathrm{H}$ was administered in September. Test-retest and alternate forms reliabilities for these subtests are not reported in the WRMT-R manual.

Test of Word Reading Efficiency (TOWRE; Torgesen, Wagner, \& Rashotte, 1999). The Sight Word Efficiency subtest measures an examinee's level of reading fluency by assigning a task whereby the child reads as many printed real words as possible within 45 seconds. The reported alternate-form reliability values for this subtest range from 0.91 to 0.95 ( $\mathrm{p}$. 60) across demographic samples, and the reported test-retest reliability is 0.84 for Form A and 0.92 for Form B (p. 62). The Phonemic Decoding Efficiency subtest measures how many pronounceable printed nonwords a participant can decode within 45 seconds. Reported alternateform reliability values for this subtest range from 0.91 to 0.94 (p. 60) across the age groups tested, and the reported test-retest reliability is 0.89 for Form A and 0.83 for Form B (p. 62). For both of the TOWRE subtests, we administered Form A in May/June and Form B in September.

Peabody Picture Vocabulary Test-III (PPVT-III; Dunn \& Dunn, 1997). In this test of receptive vocabulary, the examiner reads a word aloud and the student must choose from among four pictures which one best represents the word. The reported alpha value for Form IIIA is 0.95 and for Form IIIB is 0.96 (p. 50). The reported test-retest reliability for both forms ranges from 0.91 to 0.94, across the age groups tested (p. 51). Form IIIA was administered in May/June and Form IIIB was administered in September. Reported alternate-form reliability for the PPVTIII ranges from 0.94 to 0.96 across the age groups tested (p. 49).

\section{Procedure}

All participants were tested individually by one of four trained examiners in separate and quiet rooms in their respective schools. A Licensed Psychologist with expertise in reading disabilities individually trained all four examiners. The testing of the RD group occurred prior to the summer vacation in the third week of May and again in the third week of September. Testing for the comparison group occurred in either the last week of May or the first week of June, and again in the last two weeks of September. All participants were administered the test battery in the following order at both testing sessions: Peabody Picture Vocabulary Test; WRMT-R Word Identification, Word Attack, and Passage Comprehension; TOWRE Sight Word Efficiency and Phonemic Decoding Efficiency; and CTOPP Elision and Blending Words. Test session durations were approximately 50 minutes for each participant. All scores were transformed into standard scores for comparison purposes. Following the summer vacation, phone interviews were conducted with parents to investigate the summer reading habits of both groups. None of the parents of the RD group indicated that their children had been involved in a structured summer reading program. One parent of a comparison group student indicated that his/her child had been involved in weekly reading/writing instruction (one hour per week during the month of August). 


\section{Data Analysis}

We conducted eight separate $t$ tests to assess the significance of RD vs. comparison group membership on the regression of early literacy skills over time, one for each of the eight dependent variables. This was done by calculating a regression score for each student by subtracting his or her score on each of the measures in September from his or her score on that same measure in May. If a significant $t$ test was calculated, that would mean that one group would have shown significantly more regression on the given measure than the other group. As stated above, we hypothesized that on all measures the RD group would demonstrate greater regression. If a significant result was found, then post-hoc analysis was performed on the RD group's scores alone to determine whether the degree of regression was statistically significant in itself, or just as compared to the level of regression in the other group. Cohen's $d$ was used to measure the effect size for the $t$-test analyses. Cohen's $d$ indicates the amount of difference between two groups of scores in standard deviation units. A Cohen's $d$ value of 0.2 is generally taken to represent a small effect, 0.5 a medium effect, and 0.8 a large effect.

Given the relatively small sample size, corrections for Type I error should be considered. We used the Bonferroni correction to determine whether a result was statistically significant. In this case, the scores on eight separate measures were subjected to $t$-test analysis, so $p<.05 / 8=$ .006 was considered a statistically significant result. For the post-hoc analyses, a $p$-value of .017 was considered significant, as there were three $t$ tests computed.

\section{Results}

Means, standard deviations, and Cronbach's alpha reliabilities for the eight subtests are presented in Table 1. Visual inspection of the mean scores reveals that the comparison group participants scored higher on all measures included in the test battery, and all reliability estimates are at least 0.70 or higher, indicating good reliability (Cronbach, 1951). Table 2 shows the means and standard deviations for the regression scores on the eight subtests. Positive means indicate regression, while negative means indicate that scores increased on that measure. Generally, the scores of students in the comparison group tended to increase, while there were instances of regression in the RD group's scores.

Table 1

Means and Standard Deviations of Reading Achievement Scores for $R D$ and Comparison Groups in May and September

\begin{tabular}{|c|c|c|c|c|c|c|c|c|c|c|}
\hline & \multicolumn{5}{|c|}{$\mathrm{RD}$} & \multicolumn{5}{|c|}{ Comparison } \\
\hline & \multicolumn{2}{|c|}{$\begin{array}{c}\text { May } \\
(N=30)\end{array}$} & \multicolumn{2}{|c|}{$\begin{array}{l}\text { September } \\
(N=30)\end{array}$} & \multirow[b]{2}{*}{$\alpha$} & \multicolumn{2}{|c|}{$\begin{array}{c}\text { May } \\
(N=30)\end{array}$} & \multicolumn{2}{|c|}{$\begin{array}{l}\text { September } \\
(N=30)\end{array}$} & \multirow[b]{2}{*}{$\alpha$} \\
\hline & $M$ & $S D$ & $M$ & $S D$ & & $M$ & $S D$ & $M$ & $S D$ & \\
\hline CTOPP Elision & 7.43 & 2.81 & 8.30 & 2.40 & 0.83 & 9.80 & 2.67 & 10.17 & 2.32 & 0.84 \\
\hline Blending Words & 8.43 & 2.50 & 7.97 & 1.79 & 0.70 & 8.87 & 2.40 & 8.30 & 1.99 & 0.74 \\
\hline WRMT Word Attack & 91.07 & 6.38 & 91.10 & 9.28 & 0.82 & 99.10 & 7.44 & 102.53 & 12.37 & 0.82 \\
\hline Word Identification & 91.13 & 10.71 & 87.83 & 10.83 & 0.97 & 97.67 & 9.37 & 97.83 & 11.02 & 0.93 \\
\hline Passage Comprehension & 87.43 & 12.43 & 89.27 & 11.82 & 0.72 & 101.13 & 11.53 & 100.10 & 9.83 & 0.87 \\
\hline TOWRE Sight Word Efficiency & 87.97 & 14.97 & 82.97 & 12.81 & 0.94 & 101.40 & 12.89 & 106.03 & 13.28 & 0.94 \\
\hline Phonemic Decoding Efficiency & 88.21 & 16.11 & 82.76 & 11.74 & 0.86 & 98.14 & 13.40 & 103.79 & 15.92 & 0.71 \\
\hline PPVT-III & 104.57 & 11.84 & 103.80 & 13.68 & 0.86 & 105.33 & 12.17 & 105.23 & 11.43 & 0.84 \\
\hline
\end{tabular}


Table 2

Means and Standard Deviations of Summer Regression Scores for $R D$ and Comparison Groups

\begin{tabular}{|c|c|c|c|c|}
\hline & \multicolumn{2}{|c|}{ RD Group } & \multicolumn{2}{|c|}{ Comparison Group } \\
\hline & $M$ & $S D$ & $M$ & $S D$ \\
\hline CTOPP Elision & -0.87 & 0.36 & -0.37 & 0.34 \\
\hline Blending Words & -0.43 & 0.43 & -0.33 & 0.31 \\
\hline WRMT Word Attack & -0.03 & 1.14 & -3.43 & 1.45 \\
\hline Word Identification & 3.30 & 0.68 & -0.17 & 0.95 \\
\hline Passage Comprehension & -1.83 & 2.07 & 1.03 & 1.33 \\
\hline TOWRE Sight Word Efficiency & 5.00 & 1.69 & -4.63 & 1.17 \\
\hline Decoding Efficiency & 5.45 & 1.82 & -5.66 & 2.58 \\
\hline PPVT- III & 0.77 & 1.64 & 0.10 & 1.59 \\
\hline
\end{tabular}

Note. CTOPP = Comprehensive Test of Phonological Processing; WRMT = Woodcock Reading Mastery Test-Revised; TOWRE = Test of Word Reading Efficiency; PPVT = Peabody Picture Vocabulary Test III.

There was no significant difference in the degree of regression between the RD and comparison groups on the following measures: the CTOPP Elision subtest, $t(58)=1.002, p=.320, d$ $=1.43$; the CTOPP Blending Words subtest, $t(58)=0.188, p=.851, d=0.27$; the WRMT-R Word Attack subtest, $t(58)=-1.841, p=.071, d=2.61$; the WRMT-R Passage Comprehension subtest, $t(58)=1.166, p=.248, d=1.64$; and the PPVT-III, $t(58)=-0.292, p=.771, d=0.41$.

Significant differences between the regression scores of the RD and comparison groups were found on the two subtests of the TOWRE, Sight Word Efficiency, $t(58)=-5.821, p<.001$, $d=1.50$, and Phonemic Decoding Efficiency, $t(56)=-3.512, p=.001, d=0.92$, and on the WRMT-R Word Identification subtest, $t(58)=-2.969, p=.004, d=0.77$. Therefore, we conducted post hoc testing to determine whether the RD group alone did indeed demonstrate significant regression. Follow-up paired-samples $t$ tests indicated that the RD group showed significant regression in performance over the summer on Sight Word Efficiency, $t(29)=4.279, p<$ $.001, d=0.36$, Phonemic Decoding Efficiency, $t(28)=2.993, p=.006, d=0.39$, and Word Identification, $t(29)=4.887, p<.001, d=0.31$.

\section{Discussion}

The purpose of the current study was to test for differential effects of the summer vacation on the reading achievement of students with RD as compared to their non-RD peers. We hypothesized that the RD group would show significant losses in terms of phonological processing, phonological awareness, reading fluency, vocabulary, and reading comprehension over the summer months and that the pre- and post-summer scores of the non-RD comparison group would remain relatively stable, with only slight losses (consistent with previous research; Cooper et al., 1996). These hypotheses were partially confirmed in that the comparison group either remained stable or increased on all measures (the significance of the increase was not examined, as this information was not pertinent to the research question), but the RD group regressed significantly only on three of the eight subtests. Interesting implications are apparent in considering those reading measures on which the RD group did demonstrate the expected regression.

Specifically, the RD group showed the expected pattern of regression on the TOWRE Sight Word Efficiency, TOWRE Phonemic Decoding Efficiency, and WRMT-R Word Identification subtests, all of which require that examinees have acquired a substantial degree of proficiency with automatic decoding or fluent phonological processing. As mentioned previously, Wagner and Torgesen (1987) proposed that phonological processing plays a causal role in learning to read and in the reading difficulties experienced by individuals with RD. Phonological 
processing deficits are also consistent with the double-deficit hypothesis theory of dyslexia, which posits that phonological impairments, in addition to naming-speed deficits, are the causal factors underlying dyslexia (Wolf \& Bowers, 1999). The idea that phonological deficits underlie early reading skills is consistent with the present finding that following a prolonged period of disuse of their phonological processing skills as they relate to reading, students with RD appear to lose the ability to apply these skills in an automatic manner (i.e., they can no longer apply this knowledge fluently).

The lack of significant regression on the WRMT-R Word Attack subtest suggests that the RD group did not actually lose the ability to decode non-words. The fact that the RD group's scores did regress significantly on the subtests of the TOWRE (a test of word and non-word reading administered under timed conditions) and the WRMT-R Word Identification subtest suggests that this group instead regressed in terms of the speed at which they were able to decode and the speed at which they could name real words. All three of these subtests require that examinees have acquired a substantial degree of proficiency with automatic decoding, or fluent phonological processing (despite the fact that the Word Identification subtest is not officially timed). This effect may not have been found on the WRMT-R Word Attack subtest because the participants were given approximately 5 seconds to respond (Woodcock, 1998), rather than being asked to read as many words as they can as quickly as possible as in the TOWRE subtests (Torgesen et al., 1999), or to read real words as in the Word Identification subtest, which may have contributed to increased pressure to read the words quickly given that they were words that the students should have seen before.

The results of the current study are also consistent with Chall's (1983) five-step model of reading development, which posits that the child must first understand letter-sound relationships in order to gain the ability to decode printed words, and then reading fluency is gained through practice. For average readers, reading fluency develops by Grade 4 (Chall, 1983). As evidenced by the presence of significant regression on tests that require automatic decoding, the current results suggest students with RD, following an extended lack of reading practice, tend to lose the ability to read fluently. In other words, it appears that the summer vacation disrupts previouslyacquired levels of reading fluency in the RD students, but not in their typically-achieving peers. Typical readers either retain their fluent reading skills throughout an extended absence from continuing practice with reading or regain this ability more quickly upon returning to school. The $\mathrm{RD}$ group showed deficiencies in the underlying foundations of reading development, which was further compromised during an extended period of absence from reading practice. So, the RD students have not yet been able to consolidate their early literacy skills (as would be expected by grades 4 to 6); a milestone that is required in maintaining these skills over time.

It might be noted that the effect sizes obtained for the RD group's regression on fluent reading skills over the summer were in the small-to-moderate range. Although the effect sizes were not large, it is believed that they likely still signify important regression in early literacy skills. This is especially true when the fact that small-to-medium change was found after only a 2-month period. If students with RD experience a compounding effect of increased summer reading loss upon returning to school every September, and if they are not able to catch up during the school year, these effects are likely to increase over multiple summers. The current results might be interpreted as an important warning sign that summer regression in students with RD could represent a serious problem as these students progress through school.

It should also be noted that there may be other factors that contribute to regression in the $\mathrm{RD}$ group. Those in the RD group were in classes with approximately 15 students and teachers 
with expertise in reading disabilities tailored instruction to their needs. The lack of such favourable conditions in typical classrooms might play a role in greater regression in most students with RD. Additionally, it has been shown that teachers rate students with reading problems and RD as being less motivated to do their best academically and as not being able to work as independently as their typically-achieving peers (Zentall \& Beike, 2012). Factors such as the quality of classroom instruction and the students' own levels of motivation to perform academically are also likely to impact the extent of summer regression.

\section{Prevention of Summer Learning Loss}

It is established that good readers are more likely to be exposed to print materials and to practice reading skills (Grant et al., 2007). In the context of the current study, this suggests that if students with RD are losing the ability to decode fluently to a greater extent than their non-RD peers during summer breaks, they will become increasingly disadvantaged in their reading skills development and may not acquire an adequate knowledge base to be successful in the later stages of reading (Snider \& Tarver, 1987). Also, students with RD who cannot read fluently will likely not read for pleasure to promote continuing literacy-related gains when not in school. According to Chard et al. (2002), interventions that will be effective in increasing reading fluency in students with learning disabilities involve multiple opportunities to read repeatedly familiar text both independently and with corrective feedback. Thus, extensive print exposure, which is obtained through both guided repeated oral reading and independent silent reading, is an important element in increasing the reading fluency of students with RD (National Institute of Child Health and Human Development, 2000).

Additionally, changes to the structure of the school calendar might also contribute to a lessening in summer regression in students with $\mathrm{RD}$. The traditional school calendar is defined as one that consists of 180 days of instruction and operates for 9 months, from September to June, with a 2-month summer vacation (Stenvall \& Stenvall, 2001). In their review, Cooper, Valentine, Charlton, and Melson (2003) highlight alternatives to the traditional school calendar. One such alternative is the extended school year program, which actually increases the number of days that students spend in school. Other alternatives involve different distributions of school days and breaks, which may or may not require an increase in the number of days spent in school. Research looking at the extent of regression during these shorter break times for RD students is not currently available, but should be investigated in future studies.

Literature relating to the effectiveness of modified calendars on learning regression in general is mixed. Cooper et al. (2003) reported that students on a modified school calendar perform slightly better in school than students who are on a traditional school calendar. This effect was noted across all grade levels considered within the meta-analysis, and across subject areas. Cooper (2004) reported no significant differences between achievement scores across two calendar arrangements. However, Cooper does suggest that this effect may not generalize to mathematics skills, which tend to decline over the summer vacation for students on traditional school calendars, or to lower-SES children, who have been shown to experience substantial losses in reading skills over the summer (Allington \& McGill-Franzen, 2003; McGill-Franzen \& Allington, 2008). As mentioned, to date, no studies of the effects of modified school calendar on students with RD have been reported.

Another solution for the prevention of summer learning loss is the implementation of effective summer school programs or guided reading initiatives. Cooper (2003) stated that the effects of summer learning loss can be used to argue for increasing students' access to summer school. 
In line with this argument, Cooper, Charlton, Valentine, and Muhlenbruck (2000) found that summer school programs, which focus on remedial, accelerated, or enriched learning have a positive impact on the knowledge and skills of participants. They qualify this finding in saying that students from middle-class homes are more likely than students from disadvantaged homes to benefit from summer school programs, and that such programs may have more positive effects on mathematical skills than on reading. Kim (2006) found that summer reading programs can improve the post-summer scores of children who are less fluent readers and that reading programs are especially effective when they include a scaffolding component (Kim \& White, 2008). It remains to be seen whether this finding will also be applicable to students with specific RD diagnoses.

One example of a summer program that has some evidence in reversing the summer learning phenomenon comes from Graham et al. (2011). These authors implemented a 5-week reading intervention that included a family involvement piece. Participants and their parents were exposed to nine 2-hour sessions over the course of 5 weeks, which focused on three primary areas: print awareness, phoneme awareness, and letter-sound knowledge. Lessons were tailored around these three key elements to meet the students' individual needs. The idea was to encourage families to make literacy-based activities a part of their everyday lives. All of the families in the study were considered to be of low SES, thus placing the children at higher risk for summer learning loss (e.g., Cooper et al., 1996). However, as a result of participating in Graham et al.'s summer intervention, the expected regression effect was in fact reversed, in that at-risk students actually demonstrated gains in early literacy skills over the summer. As noted above, it is important to recognize the small sample size of this study as well as the fact that the intervention was administered to very young children. However, the results are nonetheless encouraging in terms of summer learning trends for at-risk students.

In addition to tailoring interventions for students who are at-risk because of low SES, the present results also speak to the need specifically to tailor summer programs to the needs of students with RD. Research on intervention for children with RD has shown that successful programs must be intense, of sufficient duration, and targeted on specific skills (Torgesen, Wagner, Rashotte, Rose et al., 1999). Summer programs for students with RD need to include these characteristics, and based on the results of the current study, skills such as phoneme segmentation and rapid word naming should be targeted to help the student with RD develop and maintain reading fluency. Results such as those from Graham et al. (2011) suggest that summer interventions for children with reading problems should prove to be a worthwhile endeavour. However, because students do not tend to be diagnosed with RDs until around Grade 3 (Learning Disabilities Association of Canada, 2007), programs such as the one suggested by Graham et al. will need to be broadened in order to be applicable to older RD-diagnosed children and their families.

In terms of the implications of summer learning loss for teachers, these professionals should be aware that summer loss is especially salient in children who struggle with reading during the school year. Teachers could coordinate more directly with families, providing access to reading materials over the summer months that are consistent with the children's literacy needs, and encouraging parents and children to stay involved with reading over the summer break from school. Teachers could also follow up with at-risk children in September. They could help these readers to regain their pre-summer skills through systematic and intensive review efforts that focus on the key elements of literacy learning (Torgesen, Wagner, Rashotte, Rose et al., 1999). 


\section{Limitations}

As mentioned previously, one limitation of the present study was the differing locations and school environments of the two groups, as well as differences in the types of schools attended. It is possible that, because the groups were not created using random selection or random assignment, the differences between the two groups' regression could be attributable to other factors. It should be acknowledged that factors other than RD/comparison group status (e.g., school setting, location, and/or learning environment) could have accounted for the differences in the amount of summer regression across the two groups.

Second, since participants were tested twice over a relatively short period, test-retest reliability and practice effects must be considered. Although test-retest reliability values for all measures in the test battery are relatively high, these values may not be appropriately applied across testing sessions that occur so close together. Particularly for those tests which do not have alternate forms (e.g., the CTOPP), practice effects associated with the testing might have masked some effects that would have been found otherwise. However, because the test battery was consistent across groups and time, the possibility of practice effects should be equally applicable to both the RD and the comparison group students' scores, although the possibility that practice effects could have been stronger in the comparison group cannot be fully ruled out.

Furthermore, some tests may not be adequately sensitive to changes in performance over a relatively short period. Significant effects might have been found on the WRMT-R Word Attack and Passage Comprehension subtests if the item gradient were not so steep, in that a small but important difference of, for example, two correct versus incorrect items may have been found to be non-significant, whereas a subtest that included more items might have yielded significant results because there would be more room for change. Additionally, using standard score comparisons instead of raw score comparisons as suggested by Cooper et al. (1996) might also have contributed to the insensitivity to change of the test measures since standard score gradients tend to be steeper than raw score gradients.

Finally, pre-summer testing took place before the end of the school year, and post-summer testing took place after the students had been in school for up to three weeks. Students could have learned more after May testing, and/or relearned some information lost over the summer in the first few weeks of September. Larger effect sizes would likely have been found if participants were tested on the last school day in June and on the first day in September. It was the RD group, however, that was tested later into September, so it is remarkable that significant regression was found despite the fact that the power to detect change in this group was lessened by the fact that these students had been in school for up to an additional two weeks by the time they were tested.

\section{Future Research}

Future research should seek to address these limitations, and to look at other measures on which it would be reasonable to expect that students with RD would regress. For example, regression in spelling skills and other literacy-related skills could be investigated. Also, future studies could investigate whether there are any differences across age groups or grade levels, or whether there exist any protective factors against summer learning loss (e.g., SES, family environment). Additionally, it would be useful to include a third group consisting of students with $\mathrm{RD}$ who are enrolled in a summer reading program in order to examine whether participation in such a program attenuates the summer learning loss seen in this group. Unfortunately, the inclusion of a third group was not feasible within the constraints of the present study, thus constituting another limitation, which should be addressed by future work. Finally, future research should 
consider the possibility of an additive effect of summer regression across multiple summers wherein consistent summer setbacks lead to overall lower literacy and reading achievement in students with RD.

\section{Conclusions}

The results of the current study suggest that students with RD demonstrate regression on tests that require automatic decoding and speeded and fluent reading. This is an important finding as it is possible that the summer vacation could have an additive effect in which each year, regression in the skills of students with RD tends to lower their scores considerably and they may not recover as readily from this summer regression. This potential drop in literacy skills every summer could lead to consequences such as lower educational attainment and related issues with employability (Statistics Canada, 2006). This would mean that the summer is a very important time for intervention efforts within the RD population. The implications of significant summer regression in reading fluency point to the potential importance of either extended school calendars or targeted summer reading interventions for RD students, specifically. While the present study does not shed light on which of these solutions would best serve students with RD, it does point to summer regression in reading fluency as being a significant concern for this population, and to the summer break as an important point of intervention for at-risk students.

\section{References}

Alexander, K. L., Entwisle, D. R., \& Olson, L. S. (2001). Schools, achievement, and inequality: A seasonal perspective. Educational Evaluation and Policy Analysis, 23, 171-191. doi:10.3102 /01623737023002171

Alexander, K. L., Entwisle, D. R., \& Olson, L. S. (2007). Lasting consequences of the summer learning gap. American Sociological Review, 72, 167-180. doi:10.1177/000312240707200202

Allington, R. L., \& McGill-Franzen, A. M. (2003). The impact of summer loss on the reading achievement gap. Phi Delta Kappan, 85, 68-75. http://pdkintl.org/publications/kappan/

Anthony, J. L., \& Lonigan, C. J. (2004). The nature of phonological awareness: Converging evidence from four studies of preschool and early grade children. Journal of Educational Psychology, 96, 43-55. doi:10.1037/0022-0663.96.1.43

Chall, J. (1983). Stages of reading development. New York, NY: McGraw-Hill.

Chard, D. J., Vaughn, S., \& Tyler, B. J. (2002). A synthesis of research on effective interventions for building reading fluency with elementary students with learning disabilities. Journal of Learning Disabilities, 35, 386-406. doi:10.1177/00222194020350050101

Cohen, J. (1988). Statistical power analysis for the behavior sciences (2nd ed.). Hillsdale, NJ: Lawrence Erlbaum Associates.

Cooper, H. (2003). Summer learning loss: The problem and some solutions. Retrieved from http://www.eric.ed .gov/PDFS/ED475391.pdf.

Cooper, H. (2004). Is the school calendar dated? Education, economics, and the politics of time. In G. D. Borman \& M. Boulay (Eds.), Summer learning: Research, policies, and programs (pp. 3-24). Mahwah, NJ: Lawrence Erlbaum Associates.

Cooper, H., Charlton, K., Valentine, J. C., \& Muhlenbruck, L. (2000). Making the most of summer school: A meta-analytic and narrative review. Monographs of the Society for Research in Child Development, 65, 1-118. http://onlinelibrary.wiley.com/journal/10.1111/(ISSN)1540-5834

Cooper, H., Nye, B., Charlton, K., Lindsay, J., \& Greathouse, S. (1996). The effects of summer vacation on achievement test scores: A narrative and meta-analytic review. Review of Educational Research, 66, 227-268. doi:10.3102/00346543066003227

Cooper, H., Valentine, J. C., Charlton, K., \& Melson, A. (2003). The effects of modified school calendars on student achievement and on school and community attitudes. Review of Educational Research, 73, 152. doi:10.3102/00346543073001001 
Cornelius, P. L., \& Semmel, M. I. (1982). Effects of summer instruction on reading achievement regression of reading disabled students. Journal of Learning Disabilities, 15, 409-413. doi:10.1177 /002221948201500707

Cronbach, L. J. (1951). Coefficient alpha and the internal structure of tests. Psychometrika, 16, 297-334. doi:10.1007/BF02310555

Cunningham, A. E., \& Stanovich, K. E. (1990). Assessing print exposure and orthographic processing skills in children: A quick measure of reading experience. Journal of Educational Psychology, 82, 733-740. doi:10.1037/0022-0663.82.4.733

Dunn, L., \& Dunn, L. (1997). Peabody Picture Vocabulary Test-Revised. Circle Pines, MN: American Guidance Services.

Ehri, L. C. (2005). Learning to read words: Theory, findings, and issues. Scientific Studies of Reading, 9, 167188. doi:10.1207/s1532799xssr0902 4

Entwisle, D. R., \& Alexander, K. L. (1992). Summer setback: Race, poverty, school composition, and mathematics achievement in the first two years of school. American Sociological Review, 57, 72-84. doi:10 $.2307 / 2096145$

Fletcher, J. M., Lyon, G. R., Fuchs, L. S., \& Barnes, M. A. (2007). Learning disabilities: From identification to intervention. New York, NY: The Guilford Press.

Graham, A., McNamara, J. K., \& Van Lankveld, J. (2011). Closing the summer learning gap for vulnerable learners: An exploratory study of a summer literacy programme for kindergarten children at-risk for reading difficulties. Early Child Development and Care, 181, 575-585. doi:10.1080 /03004431003646525

Grant, A., Wilson, A. M., \& Gottardo, A. (2007). The role of print exposure in reading skills of postsecondary students with and without reading disabilities. Exceptionality Education Canada, 17, 175-194.

Hoover, W. A., \& Gough, P. B. (1990). The simple view of reading. Reading and Writing, 2, 127-160. doi:10 $.1007 / \mathrm{BF} 00401799$

Kim, J. S. (2004). Summer reading and the ethnic achievement gap. Journal of Education for Students Placed at Risk, 9, 169-188. doi:10.1207/s15327671espr0902 5

Kim, J. S. (2006). Effects of a voluntary summer reading intervention on reading achievement: Results from a randomized field trial. Educational Evaluation and Policy Analysis, 28, 335-355. doi:10.3102 $/ 01623737028004335$

Kim, J. S., \& White, T. G. (2008). Scaffolding voluntary summer reading for children in grades 3 to 5: An experimental study. Scientific Studies of Reading, 12, 1-23. doi:10.1080/10888430701746849

Learning Disabilities Association of Canada. (2007). Putting a Canadian Face on Learning Disabilities (PACFOLD) and the prevalence of learning disabilities. Retrieved from http://www.ldac-acta.ca/en /learn-more/ld-basics/prevalence-of-lds/56-putting-a-canadian-face-on-learning-disabilities-pacfoldand-the-prevalence-of-learning-disabilities.html.

Lyon, G. R. (1996). Learning disabilities. The Future of Children, 6, 54-76. doi:10.2307/1602494

Mather, N., \& Goldstein, S. (2001). Reading fluency. In Learning disabilities and challenging behaviors: A guide to intervention and classroom management (pp. 235-242). Baltimore, MD: Paul H. Brookes.

McBride-Chang, C., Manis, F. R., Seidenberg, M. S., Custodio, R. G., \& Doi, L. M. (1993). Print exposure as a predictor of word reading and reading comprehension in disabled and nondisabled readers. Journal of Educational Psychology, 85, 230-238. doi:10.1037//0022-0663.85.2.230

McGill-Franzen, A., \& Allington, R. L. (2008). Got books? Educational Leadership, 65, 20-23. http://www .ascd.org/publications/educational-leadership.aspx

National Institute of Child Health and Human Development. (2000). Report of the National Reading Panel: Teaching children to read. Retrieved from http://www.nichd.nih.gov/publications/nrp/findings.cfm.

Pratt, A. C., \& Brady, S. (1988). Relation of phonological awareness to reading disability in children and adults. Journal of Educational Psychology, 80, 319-323. doi:10.1037//0022-0663.80.3.319

Snider, V. E., \& Tarver, S. G. (1987). The effect of early reading failure on acquisition of knowledge among students with learning disabilities. Journal of Learning Disabilities, 20, 351-356. doi:10.1177 /002221948702000610

Statistics Canada. (2006). The importance of functional literacy: Reading and math skills and labour market outcomes of high school dropouts. (Catalogue no. 11F0019MIE). Ottawa, ON: R. Finnie \& R. Meng. 
Statistics Canada. (2010). Selected income concepts for economic families of two persons or more by province, 2010. Retrieved from http://www.statcan.gc.ca/daily-quotidien/120618/t120618b002-eng.htm.

Stenvall, J. T., \& Stenvall, M. J. (2001). An analysis of 2000 API scores for California public schools on traditional and year-round calendars at elementary, middle, and high school levels. San Diego, CA: National Association for Year-Round Education (NAYRE).

Torgesen, J. K., Wagner, R. K., \& Rashotte, C. A. (1999). Test of Word Reading Efficiency. Austin, TX: ProEd.

Torgesen, J. K., Wagner, R. K., Rashotte, C. A., Rose, E., Lindamood, P., Conway, T., \& Garvin, C. (1999). Preventing reading failure in young children with phonological processing disabilities: Group and individual responses to instruction. Journal of Educational Psychology, 91, 579-593. doi:10.1037 //0022-0663.91.4.579

Troia, G. A. (2004). Phonological processing and its influence on literacy learning. In C. A. Stone, E. R. Silliman, B. J. Ehren, \& K. Apel (Eds.), Handbook of language and literacy: Development and disorders (pp. 271-301). New York, NY: The Guilford Press.

Wagner, R. K., \& Torgesen, J. K. (1987). The nature of phonological processing and its causal role in the acquisition of reading skills. Psychological Bulletin, 101, 192-212. doi:10.1037//0033-2909.101.2.192

Wagner, R. K., Torgesen, J. K., \& Rashotte, C. A. (1999). Comprehensive Test of Phonological Processing. Austin, TX: Pro-Ed.

Wolf, M., \& Bowers, P. G. (1999). The double-deficit hypothesis for the developmental dyslexias. Journal of Educational Psychology, 91, 415-438. doi:10.1037//0022-0663.91.3.415

Woodcock, R. W. (1998). WRMT-R: Woodcock Reading Mastery Tests-Revised. Circle Pines, MN: American Guidance Services.

Yopp, H. K., \& Yopp, R. H. (2000). Supporting phonemic awareness development in the classroom. The Reading Teacher, 54, 130-143. doi:10.1598/RT.54.2.2

Zentall, S. S., \& Beike, S. M. (2012). Achievement of social goals of younger and older elementary students: Response to academic and social failure. Learning Disability Quarterly, 35, 39-53. doi:10.1177 /0731948711429009

\section{Authors' Note}

Correspondence concerning this article should be addressed to Jessica Menard, Psychology Department, University of Windsor, 401 Sunset Ave., Windsor, ON, Canada, N9B 3P4.

Email: jmnrd@mta.ca 